\title{
Associations between weight loss difficulty, disordered eating behaviors and poor weight loss outcomes in Arab female university students
}

\author{
Catherine Nasrallah ${ }^{\mathrm{a}, 1}$, Linda Kimmel ${ }^{\mathrm{b}}$, Salma M. Khaled ${ }^{\mathrm{a}, *}$ \\ ${ }^{\text {a }}$ Social and Economic Survey Research Institute, Qatar University, Doha, Qatar \\ ${ }^{\mathrm{b}}$ Institute for Social Research, University of Michigan, Ann Arbor, MI, USA
}

\section{A R T I C L E I N F O}

\section{Keywords:}

Perceived weight loss difficulties

Disordered eating

Eating behaviors

Arab women

University students

\begin{abstract}
A B S T R A C T
Little is known about the impact of eating behaviors on weight management efforts among college students in non-Western settings. This study aimed to explore the relationship between eating behaviors, weight loss outcomes, and perceived weight loss difficulties (PWLD) among young Arab women trying to lose weight. A crosssectional probability sample was used to recruit female university students aged 18 years and older in the state of Qatar. Participants $(N=937)$ completed an online survey measuring their attitudes and behaviors towards healthy eating, body image, and weight loss. More than two third (67.2\%) reported facing difficulties when trying to lose weight and around one-third (31.2\%) screened positive for disordered eating. Chi-squared and logistic regression analyses showed a strong and independent association between unsuccessful weight loss including lack of weight loss or maintenance after weight loss attempts, and PWLD (OR 8.6, $p=.002$ ). In addition, eating meals a few hours before sleeping (OR 1.98; $p=.02$ ) and having disordered eating (OR 2.28; $\mathrm{p}=.02$ ) were positively associated with PWLD. BMI, weight loss goal and skipping breakfast were not associated with PWLD after adjustment for all covariates. Future studies are needed to develop better tools to comprehensively assess PWLD and validate against short- and long-term measured weight loss outcomes.
\end{abstract}

\section{Introduction}

Over the last decade, obesity has reached epidemic proportions worldwide and currently constitutes a major public health problem (Tauqeer, Gomez, \& Stanford, 2018). Studies in the Arabian Gulf report an increasing prevalence of overweight and obesity among women, with rates among the highest in the world (Musaiger \& Al-Hazzaa, 2012; Ng et al., 2011). Over the past three decades Qatar became the fastest growing country in the Arabian Gulf that witnessed great economic development and wealth (F. M. H. Ali, Nikoloski, Reka, Gjebrea, \& Mossialos, 2014; Ng, Zaghloul, Ali, Harrison, \& Popkin, 2011). The rapid modernization and economic prosperity in the country have resulted in significant lifestyle changes, including excessive consumption of high fat and caloric foods and adoption of a largely sedentary lifestyle, leading to obesity and metabolic syndrome, especially among women (Al-Nakeeb, Lyons, Dodd, \& Al-Nuaim, 2015; F. M. H. Ali et al., 2014; Musaiger et al., 2013a; Zhao et al., 2017).

Attending university or college is a critical transition period for most young adults that is often associated with increased body weight
(Crombie, Ilich, Dutton, Panton, \& Abood, 2009; Vadeboncoeur, Townsend, \& Foster, 2015). Studies in western countries have shown that these changes are mainly related to increased psychological stress and adoption of unhealthy dietary habits including increased consumption of fast and poor quality foods away from home (Racette, Deusinger, Strube, Highstein, \& Deusinger, 2008; Vella-Zarb \& Elgar, 2009). Studies involving university students in Arabian Gulf countries reported an alarming increase in physical inactivity and obesity, especially among females (Khalaf et al., 2013; Musaiger et al., 2011). In Qatar, a study investigating lifestyle habits among university students showed that those who had the highest Body Mass Index (BMI) consumed the largest amount of unhealthy food and the smallest amount of fruits and vegetables (Al-Nakeeb et al., 2015). In addition to physical inactivity and unhealthy eating habits, less studied but perhaps as important is disordered eating (DE) which has been linked to psychological distress and higher BMI in this population (Al-Thani \& Khaled, 2018). DE constitutes eating-related attitudes and behaviors that can occur without serious eating disorders (Reba-Harrelson et al., 2009). $\mathrm{DE}$, including exercise, food and weight concerns, desire to be thinner,

\footnotetext{
* Corresponding author at: Social and Economic Survey Research Institute, Qatar University, P. O. Box 2713, Doha, Qatar.

E-mail addresses: nasralc@sutterhealth.org (C. Nasrallah), lkimmel@umich.edu (L. Kimmel), skhaled@qu.edu.qa (S.M. Khaled).

${ }^{1}$ Present address: Palo Alto Medical Foundation Research Institute, Palo Alto, CA, USA. Work completed at the Social and Economic Survey Research Institute, Qatar University, Doha, Qatar.
} 
and dissatisfaction with current body image, has been linked to a higher rate of weight loss attempts, especially among females college students with overweight and obesity (Kelly-Weeder, Jennings, \& Wolfe, 2012; Kelly-Weeder, Phillips, Leonard, \& Veroneau, 2014).

Numerous studies have shown that most people face weight loss difficulties when trying to lose weight with over $80 \%$ of dieters experiencing challenges related to achieving and maintaining their target weight-loss, and regaining all or part of it within the first year (Puhl, Quinn, Weisz, \& Suh, 2017). Despite the commonality of challenges faced by individuals when trying to lose weight, known as perceived weight loss difficulty (PWLD), few studies have assessed its relationship with physiological, psychological, and social factors. Additionally, little is known about correlates of PWLD in young women of college years. It is commonly assumed that PWLD in overweight and obese individuals is largely associated with physiological or metabolic parameters related to the additional body weight. However, it is also plausible that PWLD is associated with psychological factors (including DE) and social support or pressures to lose or gain weight in young women. Understanding psychosocial correlates of PWLD will help answer the question why some people experience weight loss difficulty, while others do not, even in the absence of differences in biological parameters like BMI or body fat-to-muscle ratio.

The current available literature suggests that PWLD may arise due to engagement in DE behaviors including, but not limited to, binge eating, frequent dieting, and skipping meals for weight loss (Dombrowski, Knittle, Avenell, Araujo-Soares, \& Sniehotta, 2014), or other compensatory behaviors focused on achieving drastic weight loss including excessive exercise, laxative, or diuretic use (Reba-Harrelson et al., 2009) (George \& Johnson, 2001; Reba-Harrelson et al., 2009; Tamim et al., 2004; Thomas, Khan, \& Abdulrahman, 2010). PWLD may also be related to unattainable weight loss goals (exceeding 10 to $15 \%$ of initial body weight). Prior studies showed a strong relationship between unrealistic weight loss goals, disappointment with initial weight loss attempts, and unsuccessful long-term weight loss outcomes, including lack of weight loss or poor weight loss maintenance following weight loss attempts (Musaiger et al., 2016; Rogerson, Soltani, \& Copeland, 2016).

Most of the studies conducted in Qatar and other countries in the Arabian Gulf region focus on eating habits or poor dietary choices and their associations with overweight and obesity. Additionally, studies have shown that $\mathrm{DE}$ is relatively common among young females who attend post-secondary education in Arab countries ranging from $16.2 \%$ to $42.7 \%$ (Santos, Mata, Silva, Sardinha, \& Teixeira, 2015). Little is known about the relationship between DE and PWLD in young Arab women engaging in weight loss practices. Furthermore, we found no studies that report on the association between weight loss outcomes and PWLD in the context of the Middle East or other countries. Understanding their inter-relationships with PWLD, will inform targeted interventions in young women at risk of obesity in college or university populations. Therefore, the aim of the current study is to identify eating and weight-related behavioral correlates of PWLD in a large representative sample of young women in Qatar. We also set out to determine if PWLD is associated with weight loss outcomes independent of other variables. We hypothesized that PWLD will be positively associated with unhealthy eating habits, DE, unrealistic weight loss goals, and poor weight loss outcomes especially weight loss maintenance.

\section{Material and methods}

\subsection{Study design}

The study was part of a larger project that explored young Arab females' attitudes, and behaviors towards healthy eating, body image, and weight loss and was approved by Qatar University's Institutional Review Board.

Systematic stratified probability sampling was used to select a representative sample of female students aged 18 years and older and enrolled in September of 2016 at Qatar University, the largest national university in the State of Qatar. The sampling design features employed by the study was previously described in detail elsewhere (Musaiger et al., 2013b). A total of 937 participants specified whether they faced any difficulty when attempting to lose weight, which was the main dependent variable or outcome measure of the present study.

The Social and Economic Survey Research Institute of Qatar University collected the data from April to May 2016. Eligible participants received an invitation email including a link to a thirty-minute online questionnaire administered in the Qualtrics web survey platform (Qualtrics, 2005). Up to ten reminder contacts were made with each student to improve the response rate and reduce selection bias. Students were given the option to complete the survey in English or Arabic using laptops, tablets, or smartphones.

\subsection{Measures}

\subsubsection{Perceived weight loss difficulty (PWLD)}

Participants were asked whether they attempted to lose weight in the past 6 months "In the past six months, have you tried to lose weight" and were offered the response options of "Yes," "No," and "Don't Know." All those respondents answering "Yes" to the weight loss questions were asked, "Have you faced any difficulty while trying to lose weight?" (Response options "Yes," "No," and "Don't Know"). All respondents who replied "Yes" to attempting to lose weight and "Yes" to facing any difficulties" were coded as having faced PWLD. Those who responded "Yes" to the weight loss question but "No" to facing weight loss difficulties were coded as not having PWLD.

\subsubsection{Eating habits}

Frequency of eating meals away from home was assessed through the question: "How many times do you eat a meal away from home, or get take-out food?" Eight response categories were provided including: "never", "1 time a month or less", "2 to 3 times per month", "1 to 2 times per week", "3 to 4 times per week", "5 to 6 times per week", "once a day", and "more than once a day". After exploring the distribution of this positively skewed variable, the first four categories were collapsed into a low consumption level (54.9\%), 3 to 4 times per week into moderate level of consumption (25.3\%), and the last three categories into a high level of consumption (19.9\%).

Eating breakfast ("How often do you eat breakfast?") (Nurul Najwa \& Appukutty, 2018), eating late meals ("How often do you eat a meal within 1 to 2 hours before sleeping?") (Striegel-Moore et al., 2010) and taking vitamin supplements ("How often do you take vitamin supplements?”) (Mamtani et al., 2015) were measured using a seven-point scale: "never", "1 time per month or less", "2 to 3 times per month", "1 to 2 times per week", " 3 to 4 times per week", " 5 to 6 times per week" and "Every day". In the analysis, we considered "at least 3 to 4 times per week", which is equivalent to at least half the weekdays, and above as "regular" eating habits for consumption of breakfast, late meals and vitamin supplements. In the modeling stage, these variables were modeled in the same negative direction with "Not Eating Breakfast Regularly", "Eating Late Meals", and "Not Taking Vitamin Supplements Regularly" coded as poor eating behaviors.

\subsubsection{Weight management behaviors}

Watching portion size ("How often do you watch the portion sizes of your foods?") and counting calories ("How often do you track/watch/ count the calories of the foods you eat?") were assessed using a fivepoint scale: "never", "rarely", "sometimes", "usually", and "always". After exploring the distribution of these positively skewed variables, the last three categories were collapsed into a single category indicating a positive endorsement of weight-related management behaviors. Exercising to lose weight ("In the past 6 months, did you exercise strenuously to lose or control your weight?") was measured using a six 
point scale: "never", "once a month or less", "2-3 times a month", "once a week", "2 -6 times a week", and "once a day or more". In the analysis, "2-3 times a month" and above were considered as exercising strenuously to lose or control weight.

\subsubsection{Disordered Eating (DE)}

DE was measured using the Eating Attitudes Test (EAT-26) (Garner and Garfinkel, 1979). It is a widely used instrument for measuring DE in student populations. The EAT-26 was previously validated in Arabspeaking populations (Al-Adawi et al., 2002; Khaled, Kimmel, \& Le Trung, 2018). Clinically significant levels of disordered eating were denoted using a cutoff score of 20 and above (Al-Thani \& Khaled, 2018; Garner, Olmsted, Bohr, \& Garfinkel, 1982), which was used in this study to identify participants with disordered eating. The EAT-26 had a good internal consistency with a Cronbach's alpha of 0.82 and average inter-item covariance of 0.20 (Al-Thani \& Khaled, 2018).

\subsubsection{Weight loss goals and outcomes}

Weight loss goals were measured using desired percentage of weight loss, which was calculated using the participants' self-reported weight and their target weight (How much would you like to weigh?) ([(Selfreported weight - Target weight) / Self-reported weight] $* 100$ ). Previous studies showed a cutoff of $5 \%$ to $15 \%$ was ideal for efficient and healthy weight loss, especially among participants with overweight and obesity (Ryan \& Yockey, 2017).

Participants were asked to describe the results of their most recent weight loss effort ("Think about your most recent effort to lose weight. How would you describe the results?") by choosing one of the following categories: "lost all I wanted to lose and kept it off", "lost part of the weight I wanted to lose and kept it off", "lost weight, but gained some of it back", "lost weight, but gained all of it back" and "didn't lose any weight". The first two categories including weight loss and maintenance were considered positive outcomes, whereas lack of weight loss and lack of weight loss maintenance were considered negative outcomes

\subsubsection{Body mass index (BMI)}

Self-reported measures of height and weight were used to calculate current BMI and participants were classified as normal weight $(18.5 \leq$ BMI $\geq 24.9)$ and overweight or obese (BMI $\geq 25$ ). Weight loss goals including the desired amount of weight change were calculated using the absolute difference between the current self-reported body weight and the desired body weight expressed by participants ("How much would you like to weigh?").

\subsubsection{Socio-demographics and social support}

Age, nationality, number of years lived in Qatar, marital status, perceived family socioeconomic status (SES) and parents' education were also collected. Parent's highest education level completed was assessed by asking participants to choose one of the following options: "less than high school diploma", "high school diploma", "college degree", "undergraduate, graduate", or "post-graduate". Later in the analysis, the education variable was collapsed into two categories: "less than college degree" and "college degree or higher". In addition, the respondents were also asked to rate their own family's socioeconomic status as "poor", "financially challenged", "financially stable", "financially comfortable" or "wealthy". "Poor" and "financially challenged" were later collapsed into one category and "financially stable", "comfortable" and "wealthy" into another category.

Social support was measured through the positive influence exerted by the participants' mother, father, sister, brother, and friend on their intention to lose or gain weight.

\subsection{Statistical analysis}

Bivariate associations were explored between PWLD and all sample characteristics (nationality, SES, parents' education), key explanatory variables or covariates, including BMI, DE, eating habits, weight-related management behaviors, and other potential confounding variables, including weight loss outcomes and goals as well as social support. These explanatory variables were included in the analysis as they were associated with either PWLD or DE in previous studies. Weighted proportions with corresponding $95 \%$ confidence intervals (CI) were estimated for categorical variables and means with corresponding standard deviations for continuous variables. Means were compared using the adjusted Wald test for samples with a complex survey design. The Ftransformed version of the Pearson Chi-square statistic was used to correct for survey design effects on the sampling variances of the reported proportions (Heeringa, West, \& Berglund, 2011).

To explore associations between potential covariates and our main dependent variable, PWLD, separate univariate and multivariate logistic regression models were fit to the data. The univariate models explored each independent variable and its association with PWLD. Correlations among all covariates were tested using the weighted Pearson's R statistic to identify all collinear pairs $(r>0.5)$. In the multivariate modeling stage, all potential covariates were entered in a forward stepwise fashion into a fully adjusted model. A final adjusted, but reduced model was chosen based on the best fitting unweighted model using the deviance-based statistics including the Akaike Information Criterion (AIC) (Akaike, 1974)and the Baysian Information Criterion (BIC) indices (Schwarz, 1978), with smaller values indicating a better fit of the model. To check whether the results were robust, a sensitivity analysis was conducted by re-running the final unweighted model with sampling weights, while evaluating the F-adjusted mean residual goodness of fit test for the corresponding weighted final model (Hosmer, Lemeshow, \& Sturdivant, 2013). Both fully adjusted $(n=348)$ and reduced final $(n=366)$ models were based on subsamples of the overall population. Categorical variables were grouped into fewer levels to gain more power to detect statistically significant effects after establishing no significant differences between levels using the Wald test. Missing data were handled using case-wise deletion and differences in distribution of all variables were compared across complete and incomplete data sets (Supplementary Table 1). All analyses were conducted in STATA (Version 14).

\section{Results}

A total of 1767 participants responded to the weight loss attempt question, out of which 1039 reported attempting to lose weight. Sample sizes were reduced due to missing data, whereby of the 1039 who attempted to lose weight, 1032 responded to the weight loss difficulty question and 937 specified whether they faced difficulty or not out of which 630 (67.2\%) reported facing PWLD (Supplemental Fig. 1). Table 1 shows characteristics of respondents who reported PWLD versus those who did not report PWLD. Of those facing difficulties, 65.5\% were Qatari and 34.5\% were non-Qatari, and most (87.1\%) had lived in Qatar for 20 or more years. The participants' age ranged from 18 to 39 years, and only $22.9 \%$ were ever married. Over half $(62.8 \%)$ self-reported BMI in an overweight or obese category. More than one third of the participants' mothers (39.7\%) and less than half of their fathers (45.2\%) had at least a college degree. Almost all participants reported that their family was financially comfortable or wealthy (95.9\%).

Table 2 shows associations between DE, unhealthy eating habits, weight loss outcomes, weight loss goals, and PWLD before (univariate weighted models) and after adjusting for potential confounders and covariates (fully adjusted and reduced final weighted models). Findings from the univariate models showed positive associations between PWLD and higher BMI, DE, moderate-to-high frequency of eating out, eating late meals, skipping meals, lack of weight loss or maintenance and having a weight-loss goal $>15 \%$. In fact, facing difficulty while trying to lose weight was strongly related to weight loss outcomes. 
Table 1

Distribution of participants' characteristics in female students with and without perceived weight loss difficulty $(N=937)$.

\begin{tabular}{|c|c|c|}
\hline Variables & $\begin{array}{l}\text { Facing weight loss } \\
\text { difficulties } \\
(N=630) \\
\mathrm{n}(\%)\end{array}$ & $\begin{array}{l}\text { Not facing weight loss } \\
\text { difficulties } \\
(N=307) \\
\mathrm{n}(\%)\end{array}$ \\
\hline \multicolumn{3}{|l|}{ Nationality } \\
\hline Qatari & $388(64.6)$ & $216(35.4)$ \\
\hline Non-Qatari & $242(72.6)$ & $91(27.4)$ \\
\hline \multicolumn{3}{|l|}{ Socio-economic status } \\
\hline Financially challenged & $23(74.7)$ & $8(25.3)$ \\
\hline $\begin{array}{l}\text { Financially comfortable/ } \\
\text { Wealthy }\end{array}$ & $488(66.7)$ & $244(33.3)$ \\
\hline \multicolumn{3}{|l|}{ Mother's education } \\
\hline Less than college degree & $301(68.3)$ & 139 (31.7) \\
\hline College degree or higher & $200(64.5)$ & $111(35.5)$ \\
\hline \multicolumn{3}{|l|}{ Father's education } \\
\hline Less than college degree & $275(66.9)$ & $137(33.1)$ \\
\hline College degree or higher & $234(66.5)$ & $117(33.5)$ \\
\hline \multicolumn{3}{|l|}{ Lack of social support } \\
\hline Mother & $219(72.7)$ & $81(27.3)$ \\
\hline Father & $314(70.0)$ & $134(30.0)$ \\
\hline Sister & $307(71.6)$ & $123(28.4)$ \\
\hline Brother & $393(71.0)$ & $162(29.0)$ \\
\hline Friend & $270(70.0)$ & $117(30.0)$ \\
\hline \multicolumn{3}{|l|}{ Current BMI } \\
\hline Normal weight & $223(56.9)$ & $169(43.1)$ \\
\hline Overweight or obese & $375(77.5)$ & $108(22.5)$ \\
\hline \multicolumn{3}{|l|}{ EAT-26 score } \\
\hline$<20$ & $402(62.1)$ & $242(37.9)$ \\
\hline$\geq 20$ & $182(80.6)$ & $45(19.4)$ \\
\hline Eating meals away from home & $295(70.9)$ & $120(29.1)$ \\
\hline \multicolumn{3}{|c|}{ Frequency of eating meals away from home } \\
\hline Low & $334(64.1)$ & $187(35.9)$ \\
\hline Moderate & $155(67.7)$ & $73(32.3)$ \\
\hline High & $140(48.8)$ & $47(25.2)$ \\
\hline Not eating breakfast regularly & $175(60.8)$ & $112(39.2)$ \\
\hline Eating late meals & $331(72.0)$ & $129(28.0)$ \\
\hline $\begin{array}{l}\text { Not taking vitamin } \\
\text { supplements }\end{array}$ & $474(67.0)$ & $233(33.0)$ \\
\hline Not watching portion size & $141(72.1)$ & 54 (27.9) \\
\hline Not counting calories & $327(67.2)$ & $158(32.8)$ \\
\hline Skipping meals & $191(73.2)$ & $71(26.8)$ \\
\hline Not exercising vigorously & 306 (64.1) & $171(35.9)$ \\
\hline \multicolumn{3}{|l|}{ Weight loss outcomes } \\
\hline Weight loss and maintenance & $169(52.4)$ & $157(47.6)$ \\
\hline $\begin{array}{l}\text { Weight loss without } \\
\text { maintenance }\end{array}$ & $302(73.4)$ & $108(26.6)$ \\
\hline Lack of weight loss & $123(91.4)$ & $11(8.6)$ \\
\hline \multicolumn{3}{|l|}{ Weight loss goal } \\
\hline $1-10 \%$ & $68(73.8)$ & $23(26.2)$ \\
\hline $10-15 \%$ & $102(78.2)$ & $30(21.8)$ \\
\hline$>15 \%$ & $279(85.4)$ & $47(14.6)$ \\
\hline
\end{tabular}

Note. All percentages are based on weighted proportions calculated using survey weights and therefore differ from the row percentages.

Approximately $71 \%$ of the participants who reported PWLD also experienced negative weight loss outcomes including no weight loss at all or lack of weight loss maintenance compared to those who did not report PWLD. Moreover, having large weight loss targets was significantly related to facing difficulty, whereby around $85 \%$ of participants who reported PWLD compared to $78.2 \%$ of those without PWLD had a desired percentage of weight loss exceeding $15 \%$ of their reported weight (Table 1).

In addition, the univariate models showed that PWLD was negatively associated with Qatari nationality, mothers, sisters, and brothers support, not eating breakfast regularly and not exercising vigorously to manage weight.
Results from the fully adjusted and final reduced models were largely consistent (Table 2). In the final reduced model, DE and eating late meals were positively associated with PWLD even after adjustment for all other covariates. Additionally, a strong and independent association was found between lack of weight loss or maintenance and PWLD. Qatari nationality, not eating breakfast regularly, BMI and weight loss $>10 \%$ were not statistically associated with PWLD after adjustment for covariates.

\section{Discussion}

To our knowledge, this is the first study to report on PWLD and its associations with BMI, eating- and weight-related behaviors, DE, and weight loss outcomes in a representative female sample of young Arab university students. Approximately $58 \%$ of our original sample reported attempting to lose weight in the past 6 months, out of which two-thirds (67.2\%) reported facing difficulty. Compared to participants who did not report difficulty when attempting to lose weight, those with PWLD were more likely to have higher self-reported BMI (overweight or obesity), DE, and unhealthy eating and weight management behaviors, including skipping breakfast and eating late meals. Additionally, those with PWLD were significantly more likely to experience negative weight loss outcomes including difficulty in weight loss maintenance.

Our main finding pertains to the strong and positive association between poor weight loss outcomes and PWLD independent of BMI and other important covariates. For instance, weight loss and weight maintenance proved to be challenging because of the interaction between human biology, behavior and surrounding environment (Hall \& Kahan, 2018). This preliminary finding lends face validity to PWLD, which remains an understudied construct to date by suggesting that short-term (1 to 6 months) weight loss outcomes may be an important correlate of PWLD in this population. Future studies are needed to confirm these findings prospectively and to link measured weight loss outcomes with PWLD.

We also found that DE and PWLD were independently and positively associated with each other, a finding that may have important implications for early and targeted interventions among young women at risk of obesity in college or university populations. DE has been previously associated with poor weight loss outcomes among young females in Western settings including weight cycling and poor weight loss maintenance (French, Perry, Leon, \& Fulkerson, 1995; Kelly-Weeder et al., 2014; McCuen-Wurst, Ruggieri, \& Allison, 2018; Sherwood, Jeffery, \& Wing, 1999). Other plausible mechanisms may also account for this association between DE and PWLD. For example, recent studies reported strong associations between DE and non-intuitive eating or eating in the absence of hunger or after satiation (Gan \& Yeoh, 2017); DE and psychological distress (Al-Thani \& Khaled, 2018), both of which may also contribute to poor weight loss outcomes.

Eating meals late at night was positively associated with PWLD in this population. This is consistent with findings from previous studies that showed a strong relationship between having meals close to sleep time and weight gain (Reid, Baron, \& Zee, 2014). This is also consistent within the context of Qatar and other Arab Gulf countries, where eating late in the evening is a common practice, especially among women. Given the hot summer climate (Brown \& Trost, 2003) and the sociocultural norms that restrict outdoor activities, women frequently organize private evening gatherings at their homes whereby different types of food are continuously offered to invitees, which may encourage overeating and lead to weight gain (Ali, Baynouna, \& Bernsen, 2010).

To our surprise, social support was not significantly associated with PWLD after adjustment of other covariates including DE. This finding was consistent with a number of studies showing the association between social support and negative weight results including weight regain (Brantley et al., 2014; Geliebter, Astbury, Aviram-Friedman, Yahav, \& Hashim, 2014). A qualitative study conducted by Kiernan et al. showed that receiving support from friends and family is not 
Table 2

Logistic regression models for perceived weight loss difficulty.

\begin{tabular}{|c|c|c|c|c|c|c|}
\hline \multirow[t]{2}{*}{ Variables } & \multicolumn{2}{|l|}{ Unadjusted odd ratio } & \multicolumn{2}{|c|}{ Fully adjusted model $(\mathrm{n}=348)$} & \multicolumn{2}{|c|}{ Final reduced model $(\mathrm{n}=366)$} \\
\hline & U-OR ( $95 \%$ CI) & $p$-Value & OR $(95 \% \mathrm{CI})$ & p-Value & OR $(95 \% \mathrm{CI})$ & $\mathrm{p}$-Value \\
\hline Nationality & $0.69(0.52-0.91)$ & $0.01^{*}$ & $0.62(0.33-1.19)$ & 0.15 & $0.72(0.39-1.32)$ & 0.29 \\
\hline Socio-economic Status & $1.48(0.67-3.25)$ & 0.33 & $0.56(0.11-2.93)$ & 0.49 & - & - \\
\hline Father's education & $0.98(0.73-1.31)$ & 0.90 & $1.53(0.76-3.08)$ & 0.23 & $1.60(0.83-3.07)$ & 0.16 \\
\hline Mother's education & $0.84(0.62-1.13)$ & 0.25 & $0.58(0.30-1.12)$ & 0.11 & $0.65(0.35-1.19)$ & 0.16 \\
\hline Mother's support & $0.68(0.51-0.91)$ & $0.01^{*}$ & $1.21(0.57-2.59)$ & 0.61 & - & - \\
\hline Father's support & $0.78(0.6-1.02)$ & 0.07 & $0.67(0.32-1.40)$ & 0.29 & $0.69(0.37-1.31)$ & 0.26 \\
\hline Sister's support & $0.68(0.52-0.89)$ & $0.01^{*}$ & $1.29(0.63-2.64)$ & 0.49 & - & - \\
\hline Brother's support & $0.65(0.5-0.86)$ & $0.002^{*}$ & $0.49(0.22-1.12)$ & 0.09 & $0.64(0.34-1.22)$ & 0.18 \\
\hline Friend's support & $0.8(0.61-1.05)$ & 0.11 & $1.04(0.53-2.05)$ & 0.91 & - & - \\
\hline BMI & $1.1(1.05-1.15)$ & $<0.001^{*}$ & $0.98(0.91-1.05)$ & 0.51 & $0.97(0.91-1.04)$ & 0.39 \\
\hline Disordered eating (EAT26 score $\geq 20$ ) & $2.53(1.79-3.59)$ & $<0.001^{*}$ & $2.45(1.20-5.02)$ & $0.01^{*}$ & $2.28(1.13-4.61)$ & 0.02 \\
\hline Eating meals away from home & $1.17(0.85-1.61)$ & 0.33 & $0.71(0.34-1.50)$ & 0.37 & $0.89(0.45-1.77)$ & 0.75 \\
\hline Moderate/high frequency of eating meals away from home ${ }^{a}$ & $1.66(1.16-2.38)$ & $0.01^{*}$ & $1.70(0.68-4.28)$ & 0.26 & $1.75(0.77-4.01)$ & 0.18 \\
\hline Not eating breakfast regularly & $0.66(0.5-0.87)$ & $0.004^{*}$ & $0.48(0.24-0.93)$ & $0.03^{*}$ & $0.54(0.29-1.01)$ & 0.05 \\
\hline Eating late meals & $1.55(1.19-2.02)$ & $0.001^{*}$ & $2.09(1.09-3.99)$ & $0.03^{*}$ & $1.98(1.1-3.6)$ & 0.02 \\
\hline Not taking vitamin supplements & $0.96(0.71-1.31)$ & 0.80 & $1.48(0.72-3.05)$ & 0.28 & - & - \\
\hline Not watching portion size & $1.34(0.96-1.87)$ & 0.08 & $0.74(0.33-1.69)$ & 0.48 & - & - \\
\hline Not counting calories & $1.00(0.77-1.3)$ & 0.98 & $0.93(0.46-1.90)$ & 0.84 & - & - \\
\hline Skipping meals & $1.46(1.08-1.97)$ & $0.01^{*}$ & $0.60(0.31-1.14)$ & 0.12 & $0.65(0.36-1.17)$ & 0.15 \\
\hline Not exercising vigorously & $0.74(0.57-0.96)$ & $0.03^{*}$ & $0.82(0.42-1.61)$ & 0.57 & - & - \\
\hline Lack of weight loss/maintenance & $9.63(5.15-18.02)$ & $<0.001^{*}$ & $17.16(3.12-94.53)$ & $0.001^{*}$ & $8.59(2.23-33.03)$ & 0.002 \\
\hline Weight loss goal $>15 \%$ & $2.08(1.20-3.60)$ & $0.01^{*}$ & $1.67(0.57-4.98)$ & 0.35 & $1.60(0.60-4.25)$ & 0.34 \\
\hline Constant & - & - & $4.26(0.43-42.08)$ & 0.21 & $6.28(0.80-48.1)$ & 0.08 \\
\hline Log-Likelihood Full Model $^{\mathrm{b}}$ & - & - & -133.30 & - & -147.86 & - \\
\hline Chi-Square Test ${ }^{\mathrm{b}}$ & - & - & 56.46 & - & 49.70 & - \\
\hline $\mathrm{AIC}^{\mathrm{b}}$ & - & - & 412.91 & - & 329.73 & - \\
\hline $\mathrm{BIC}^{\mathrm{b}}$ & - & - & 410.34 & - & 396.07 & - \\
\hline Pseudo $\mathrm{R}^{2 \mathrm{~b}}$ & - & - & 0.17 & - & 0.14 & - \\
\hline
\end{tabular}

Note. All estimates, unless otherwise specified, are based on weighted models.

a Eating meals away from home at least 3 times/week.

b Estimates based on Unweighted Models.

* $P<.05$.

appreciated by women struggling with their weight management (Karfopoulou, Anastasiou, Avgeraki, Kosmidis, \& Yannakoulia, 2016).

Not eating breakfast regularly was negatively associated with PWLD in the bivariate analysis and in the univariate model, however it was not significantly associated with PWLD after adjustment for DE and other covariates in the multivariate reduced models. In fact, relationship between eating breakfast and weight loss difficulty remains an unclear and understudied construct to date. Earlier studies reported high prevalence of regular breakfast eaters among successful maintainers of weight loss (Ali, Baynouna, \& Bernsen, 2010; Kayman, Bruvold, \& Stern, 1990). Also, regular breakfast eating has been associated with reduced hunger and consumption of less energy dense foods and more sustained energy to carry out physical activity during the day (Wyatt et al., 2002). However, recent studies support higher success rates at short-term weight loss among those who reported skipping breakfast (Wyatt et al., 2002).

Although higher BMI was positively associated with PWLD in the bivariate analysis and in the univariate model with BMI as the only correlate of PWLD, it was not significantly associated with PWLD after adjustment for DE and other covariates in the multivariate (fully adjusted and reduced) models. Our stepwise approach in fitting these multivariate models indicated that simultaneous adjustment for effects of DE and BMI on PWLD attenuated the association between BMI and PWLD. This finding is consistent with what is already known about the strong association between DE and higher BMI (Kiernan et al., 2012) and between DE and poor weight loss outcomes (Al-Thani \& Khaled, 2018; Gan \& Yeoh, 2017; Reba-Harrelson et al., 2009).

\section{Strengths and limitations}

The large sample size and homogeneous composition of the population, predominantly young Arab women, is a major strength of the current study. However, our major limitation is the cross-sectional design of the study. Since this is a one-time measurement of exposure and outcome, it is not possible to infer causal relationships between PWLD and all the covariates. In addition, as data was gathered from a sample of Arab female students attending the largest national university in the state of Qatar, results cannot be generalized to the Qatari population. Another limitation pertains to the brevity of assessment of our main dependent variable. A largely understudied construct in the current literature, PWLD was measured in our study using one question and no information about the severity of perceived levels of difficulty in weight loss or number of weight loss attempts in the past six-months was collected. Moreover, out of concern for cultural applicability, we developed and tested lifestyle behaviors and PWLD measures that has some validity in Qatar's context as it was pilot tested with 35 participants and retested again through 20 cognitive interviews. However, these measures were not psychometrically validated in Qatar. Additionally, our final model was based on a subsample with a relatively higher proportion of participants in the normal weight range, which could limit the interpretation of some of our findings (e.g. that weight loss and maintenance of weight loss is a desirable goal for all cases). However, there is a sizeable literature on perception of being overweight being related to $\mathrm{DE}$ even in the absence of actually being overweight (Cook, MacPherson, \& Langille, 2007; Elfhag \& Rossner, 2005). Future studies are needed to show how this measure of perceived difficulty in weight loss correlates prospectively with higher energy intake, measured changes in BMI, and other measured indicators of weight loss outcomes in this population. The study is also limited by lack of information on other potential confounding variables such as physical activity and smoking status. However, given the reported low prevalence of smoking (6.0\%) and high sedentary lifestyle reaching 
$42 \%$ of Qatari women (Martin et al., 2014), these variables may not be major confounders of our findings. Furthermore, the role of sociocultural factors, including dietary customs and traditions, knowledge and attitudes of young women towards weight loss and physical activity, in relation to weight loss attempts and PWLD although of interest, were not explored and should be investigated in future studies. Identifying sociocultural markers of PWLD in the context of the Middle East and other countries may help inform targeted interventions for the prevention and management of overweight and obesity among young women in Qatar and other Arab countries. Since our study was based on an all-female sample, it is unclear how our findings would generalize to male university students. Furthermore, no correction methods were employed to correct for multiple comparisons, which is a potential limitation of our analysis.

\section{Conclusions}

Findings from this study provide evidence in support of our hypothesis that disordered eating, weight loss behaviors, and poor weight loss outcomes, including lack of weight loss or poor weight loss maintenance in the 6 months following weight loss attempt were positively associated with PWLD. DE and poor weight loss outcomes remained positively associated with PWLD independent of other variables including BMI and percentage weight loss goals. These findings will help future research to develop better tools to comprehensively assess PWLD and to link PWLD with short- and long-term measured weight loss outcomes. In addition, findings of the study will guide public health researchers in developing culturally-appropriate obesity prevention interventions by using integrated approaches that raise awareness towards healthy eating and exercising.

Supplementary data to this article can be found online at https:// doi.org/10.1016/j.eatbeh.2020.101363.

\section{CRediT authorship contribution statement}

Catherine Nasrallah:Methodology, Writing - original draft, Formal analysis, Investigation.Linda Kimmel:Methodology, Writing original draft, Formal analysis, Validation.Salma M. Khaled:Conceptualization, Investigation, Methodology, Data curation, Formal analysis, Writing - original draft.

\section{References}

Akaike, H. (1974). A new look at the statistical model identification. IEEE Trans Autom Contr, 19, 716-723.

Al-Adawi, S., Dorvlo, A. S., Al-Ismaily, S. S., Al-Ghafry, D. A., Al-Noobi, B. Z., Al-Salmi, A., ... Chand, S. P. (2002). Perception of and attitude towards mental illness in Oman. The International Journal of Social Psychiatry, 48(4), 305-317. https://doi.org/10. $1177 / 002076402128783334$.

Ali, F. M. H., Nikoloski, Z., Reka, H., Gjebrea, O., \& Mossialos, E. (2014). The diabetesobesity-hypertension nexus in Qatar: Evidence from the World Health Survey. Population Health Metrics, 12(1), 18. https://doi.org/10.1186/1478-7954-12-18.

Ali, H. I., Baynouna, L. M., \& Bernsen, R. M. (2010). Barriers and facilitators of weight management: Perspectives of Arab women at risk for type 2 diabetes. Health \& Social Care in the Community, 18(2), 219-228. https://doi.org/10.1111/j.1365-2524.2009. 00896.x.

Al-Nakeeb, Y., Lyons, M., Dodd, L. J., \& Al-Nuaim, A. (2015). An investigation into the lifestyle, health habits and risk factors of young adults. International Journal of Environmental Research and Public Health, 12(4), 4380-4394. https://doi.org/10. 3390/ijerph120404380.

Al-Thani, M. A., \& Khaled, S. M. (2018). "Toxic pleasures": A study of eating out behavior in Arab female university students and its associations with psychological distress and disordered eating. Eating Behaviors, 31, 125-130. https://doi.org/10.1016/j. eatbeh.2018.08.008.

Brantley, P. J., Stewart, D. W., Myers, V. H., Matthews-Ewald, M. R., Ard, J. D., Coughlin, J. W., ... Stevens, V. J. (2014). Psychosocial predictors of weight regain in the weight loss maintenance trial. Journal of Behavioral Medicine, 37(6), 1155-1168. https://doi. org /10.1007/s10865-014-9565-6.

Brown, W. J., \& Trost, S. G. (2003). Life transitions and changing physical activity patterns in young women. American Journal of Preventive Medicine, 25(2), 140-143.

Cook, S. J., MacPherson, K., \& Langille, D. B. (2007). Far from ideal: Weight perception, weight control, and associated risky behaviour of adolescent girls in Nova Scotia.
Canadian Family Physician, 53(4), 678-684.

Crombie, A. P., Ilich, J. Z., Dutton, G. R., Panton, L. B., \& Abood, D. A. (2009). The freshman weight gain phenomenon revisited. Nutrition Reviews, 67(2), 83-94. https://doi.org/10.1111/j.1753-4887.2008.00143.x.

Dombrowski, S. U., Knittle, K., Avenell, A., Araujo-Soares, V., \& Sniehotta, F. F. (2014) Long term maintenance of weight loss with non-surgical interventions in obese adults: Systematic review and meta-analyses of randomised controlled trials. BMJ, 348, g2646. https://doi.org/10.1136/bmj.g2646.

Elfhag, K., \& Rossner, S. (2005). Who succeeds in maintaining weight loss? A conceptual review of factors associated with weight loss maintenance and weight regain. Obesity Reviews, 6(1), 67-85. https://doi.org/10.1111/j.1467-789X.2005.00170.x.

French, S. A., Perry, C. L., Leon, G. R., \& Fulkerson, J. A. (1995). Dieting behaviors and weight change history in female adolescents. Health Psychology, 14(6), 548-555.

Gan, W. Y., \& Yeoh, W. C. (2017). Associations between body weight status, psychological well-being and disordered eating with intuitive eating among Malaysian undergraduate university students. International Journal of Adolescent Medicine and Health. https://doi.org/10.1515/ijamh-2017-0095.

Garner, D. M., \& Garfinkel, P. E. (1979). The eating attitudes test: An index of the symptoms of anorexia nervosa. Psychological Medicine, 9(2), 273-279.

Garner, D. M., Olmsted, M. P., Bohr, Y., \& Garfinkel, P. E. (1982). The eating attitudes test: Psychometric features and clinical correlates. Psychological Medicine, 12(4), 871-878.

Geliebter, A., Astbury, N. M., Aviram-Friedman, R., Yahav, E., \& Hashim, S. (2014). Skipping breakfast leads to weight loss but also elevated cholesterol compared with consuming daily breakfasts of oat porridge or frosted cornflakes in overweight individuals: A randomised controlled trial. J Nutr Sci, 3, e56. https://doi.org/10.1017/ jns.2014.51.

George, V. A., \& Johnson, P. (2001). Weight loss behaviors and smoking in college students of diverse ethnicity. American Journal of Health Behavior, 25(2), 115-124.

Hall, K. D., \& Kahan, S. (2018). Maintenance of lost weight and long-term Management of Obesity. The Medical Clinics of North America, 102(1), 183-197. https://doi.org/10. 1016/j.mcna.2017.08.012.

Heeringa, S. G., West, B. T., \& Berglund, P. A. (2011). Categorical data analysis. Applied survey data analysis. Florida, USA: Chapman Hall/CRC Press.

Hosmer, D. W., Jr., Lemeshow, S., \& Sturdivant, R. X. (2013). The multiple logistic re gression model. Applied logistic regression (pp. 2013). (3rd ed.). Hoboken, NJ, USA: John Wiley \& Sons, Inc.

Karfopoulou, E., Anastasiou, C. A., Avgeraki, E., Kosmidis, M. H., \& Yannakoulia, M. (2016). The role of social support in weight loss maintenance: Results from the MedWeight study. Journal of Behavioral Medicine, 39(3), 511-518. https://doi.org/ 10.1007/s10865-016-9717-y.

Kayman, S., Bruvold, W., \& Stern, J. S. (1990). Maintenance and relapse after weight loss in women: Behavioral aspects. The American Journal of Clinical Nutrition, 52(5), $800-807$.

Kelly-Weeder, S., Jennings, K. M., \& Wolfe, B. E. (2012). Gender differences in binge eating and behavioral correlates among college students. Eating and Weight Disorders, 17(3), e200-e202.

Kelly-Weeder, S., Phillips, K., Leonard, K., \& Veroneau, M. (2014). Binge eating and weight loss behaviors of overweight and obese college students. Journal of the American Association of Nurse Practitioners, 26(8), 445-451. https://doi.org/10.1002/ 2327-6924.12070.

Khalaf, A., Ekblom, O., Kowalski, J., Berggren, V., Westergren, A., \& Al-Hazzaa, H. (2013). Female university students' physical activity levels and associated factors-a cross-sectional study in southwestern Saudi Arabia. International Journal of Environmental Research and Public Health, 10(8), 3502-3517. https://doi.org/10. 3390/ijerph10083502.

Khaled, S. M., Kimmel, L., \& Le Trung, K. (2018). Assessing the factor structure and measurement invariance of the eating attitude test (EAT-26) across language and BMI in young Arab women. Journal of Eating Disorders, 6, 14. https://doi.org/10.1186/ s40337-018-0199-x.

Kiernan, M., Moore, S. D., Schoffman, D. E., Lee, K., King, A. C., Taylor, C. B., ... Perri, M. G. (2012). Social support for healthy behaviors: Scale psychometrics and prediction of weight loss among women in a behavioral program. Obesity (Silver Spring), 20(4), 756-764. https://doi.org/10.1038/oby.2011.293.

Mamtani, R., Cheema, S., MacRae, B., Alrouh, H., Lopez, T., ElHajj, M., \& Mahfoud, Z (2015). Herbal and nutritional supplement use among college students in Qatar. Eastern Mediterranean Health Journal, 21(1), 39-44.

Martin, B. C., Dalton, W. T., 3rd, Williams, S. L., Slawson, D. L., Dunn, M. S., \& JohnsWommack, R. (2014). Weight status misperception as related to selected health risk behaviors among middle school students. The Journal of School Health, 84(2), 116-123. https://doi.org/10.1111/josh.12128.

McCuen-Wurst, C., Ruggieri, M., \& Allison, K. C. (2018). Disordered eating and obesity: Associations between binge-eating disorder, night-eating syndrome, and weight-related comorbidities. Annals of the New York Academy of Sciences, 1411(1), 96-105. https://doi.org/10.1111/nyas.13467.

Musaiger, A. O., Al Hazzaa, H. M., Al-Qahtani, A., Elati, J., Ramadan, J., Aboulella, N. A., ... Kilani, H. A. (2011). Strategy to combat obesity and to promote physical activity in Arab countries. Diabetes Metab Syndr Obes, 4, 89-97. https://doi.org/10.2147/DMSO. S17322.

Musaiger, A. O., \& Al-Hazzaa, H. M. (2012). Prevalence and risk factors associated with nutrition-related noncommunicable diseases in the Eastern Mediterranean region. Int J Gen Med, 5, 199-217. https://doi.org/10.2147/IJGM.S29663.

Musaiger, A. O., Al-Kandari, F. I., Al-Mannai, M., Al-Faraj, A. M., Bouriki, F. A., Shehab, F. S., ... Al-Qalaf, W. B. (2016). Disordered eating attitudes among university students in Kuwait: The role of gender and obesity. International Journal of Preventive Medicine, 7, 67. https://doi.org/10.4103/2008-7802.180413. 
Musaiger, A. O., Al-Mannai, M., Tayyem, R., Al-Lalla, O., Ali, E. Y., Kalam, F., ... Chirane, M. (2013a). Perceived barriers to healthy eating and physical activity among adolescents in seven Arab countries: A cross-cultural study. ScientificWorldJournal, 2013, 232164. https://doi.org/10.1155/2013/232164.

Musaiger, A. O., Al-Mannai, M., Tayyem, R., Al-Lalla, O., Ali, E. Y. A., Kalam, F., ... Chirane, M. (2013b). Risk of disordered eating attitudes among adolescents in seven Arab countries by gender and obesity: A cross-cultural study. Appetite, 60(1), 162-167. https://doi.org/10.1016/j.appet.2012.10.012.

Ng, S. W., Zaghloul, S., Ali, H., Harrison, G., Yeatts, K., El Sadig, M., \& Popkin, B. M. (2011). Nutrition transition in the United Arab Emirates. European Journal of Clinical Nutrition, 65(12), 1328-1337. https://doi.org/10.1038/ejcn.2011.135.

Ng, S. W., Zaghloul, S., Ali, H. I., Harrison, G., \& Popkin, B. M. (2011). The prevalence and trends of overweight, obesity and nutrition-related non-communicable diseases in the Arabian Gulf States. Obesity Reviews, 12(1), 1-13. https://doi.org/10.1111/j.1467789X.2010.00750.x.

Nurul Najwa, R., \& Appukutty, M. (2018). Breakfast consumption association with body status and physical activity among female university students. Malaysian Journal of Movement, Health \& Exercise, 7(2), 93-106.

Puhl, R. M., Quinn, D. M., Weisz, B. M., \& Suh, Y. J. (2017). The role of stigma in weight loss maintenance among U.S. adults. Annals of Behavioral Medicine, 51(5), 754-763. https://doi.org/10.1007/s12160-017-9898-9.

Qualtrics (2005). Qualtrics (Version 2005). Provo, Utah, USA. Retrieved from https:// www.qualtrics.com.

Racette, S. B., Deusinger, S. S., Strube, M. J., Highstein, G. R., \& Deusinger, R. H. (2008). Changes in weight and health behaviors from freshman through senior year of college. Journal of Nutrition Education and Behavior, 40(1), 39-42. https://doi.org/10. 1016/j.jneb.2007.01.001.

Reba-Harrelson, L., Von Holle, A., Hamer, R. M., Swann, R., Reyes, M. L., \& Bulik, C. M. (2009). Patterns and prevalence of disordered eating and weight control behaviors in women ages 25-45. Eating and Weight Disorders, 14(4), e190-e198.

Reid, K. J., Baron, K. G., \& Zee, P. C. (2014). Meal timing influences daily caloric intake in healthy adults. Nutrition Research, 34(11), 930-935. https://doi.org/10.1016/j. nutres.2014.09.010.

Rogerson, D., Soltani, H., \& Copeland, R. (2016). The weight-loss experience: A qualitative exploration. BMC Public Health, 16, 371. https://doi.org/10.1186/s12889-0163045-6.

Ryan, D. H., \& Yockey, S. R. (2017). Weight loss and improvement in comorbidity: Differences at 5\%,10\%,15\%, and over. Current Obesity Reports, 6(2), 187-194. https://doi.org/10.1007/s13679-017-0262-y.

Santos, I., Mata, J., Silva, M. N., Sardinha, L. B., \& Teixeira, P. J. (2015). Predicting long term weight loss maintenance in previously overweight women: A signal detection approach. Obesity (Silver Spring), 23(5), 957-964. https://doi.org/10.1002/oby. 21082.

Schwarz, G. (1978). Estimating the dimension of a model. The Annals of Statistics, 6(2), 461-464.

Sherwood, N. E., Jeffery, R. W., \& Wing, R. R. (1999). Binge status as a predictor of weight loss treatment outcome. International Journal of Obesity and Related Metabolic Disorders, 23(5), 485-493.

Striegel-Moore, R. H., Rosselli, F., Wilson, G. T., Perrin, N., Harvey, K., \& DeBar, L. (2010). Nocturnal eating: Association with binge eating, obesity, and psychological distress. The International Journal of Eating Disorders, 43(6), 520-526. https://doi.org/ 10.1002/eat.20735.

Tamim, H., Dumit, N., Terro, A., Al-Hourany, R., Sinno, D., Seif, F., ... Musharrafieh, U. (2004). Weight control measures among university students in a developing country: A cultural association or a risk behavior. Journal of the American College of Nutrition, 23(5), 391-396.

Tauqeer, Z., Gomez, G., \& Stanford, F. C. (2018). Obesity in women: Insights for the clinician. $J$ Womens Health, 27(4), 444-457. https://doi.org/10.1089/jwh.2016. 6196.

Thomas, J., Khan, S., \& Abdulrahman, A. A. (2010). Eating attitudes and body image concerns among female university students in the United Arab Emirates. Appetite, 54(3), 595-598. https://doi.org/10.1016/j.appet.2010.02.008.

Vadeboncoeur, C., Townsend, N., \& Foster, C. (2015). A meta-analysis of weight gain in first year university students: Is freshman 15 a myth? BMC Obes, 2, 22. https://doi. org /10.1186/s40608-015-0051-7.

Vella-Zarb, R. A., \& Elgar, F. J. (2009). The 'freshman 5': A meta-analysis of weight gain in the freshman year of college. Journal of American College Health, 58(2), 161-166. https://doi.org/10.1080/07448480903221392.

Wyatt, H. R., Grunwald, G. K., Mosca, C. L., Klem, M. L., Wing, R. R., \& Hill, J. O. (2002). Long-term weight loss and breakfast in subjects in the National Weight Control Registry. Obesity Research, 10(2), 78-82. https://doi.org/10.1038/oby.2002.13.

Zhao, W., Rasheed, A., Tikkanen, E., Lee, J. J., Butterworth, A. S., Howson, J. M. M., .. Saleheen, D. (2017). Identification of new susceptibility loci for type 2 diabetes and shared etiological pathways with coronary heart disease. Nature Genetics, 49(10), 1450-1457. https://doi.org/10.1038/ng.3943. 